\title{
Qualidade microbiológica de farinhas de trigo (Triticum aestivum) comercializadas na cidade de Cascavel (Paraná)
}

\author{
Alexandre Carvalho de Moura ${ }^{1}$, Aletha Caroline Tasca $^{2}$, Fabiana Gisele da Silva Pinto ${ }^{3}$, Izabel \\ Aparecida Soares ${ }^{4}$ e Rosangela Botinha Assumpção ${ }^{5}$
}

Os cereais, em especial a farinha de trigo, são alimentos passíveis de contaminação por diferentes agentes etiológicos. O controle das condições de higiene é um dos meios para evitar conseqüências graves para a saúde humana. Com esta preocupação objetivou-se avaliar a qualidade microbiológica de farinhas de trigo comercializadas nos principais supermercados da cidade de Cascavel (PR). Para tanto, amostras de cinco marcas de farinha denominadas como A, B, C, D, e E mais comercializadas na cidade de Cascavel, foram coletadas e submetidas a avaliação microbiológica para detectar Coliformes totais, pela técnica dos tubos múltiplos do Número Mais Provável. A contagem de fungos filamentosos e de leveduras foi realizada por plaqueamento em ágar batata dextrose. De acordo com os dados analisados pelo teste de Tukey a 5\%, a marca E difere das demais quanto a variável coliformes totais. Não foi detectada a presença do contaminante Salmonella, em nenhuma das marcas analisadas. No entanto, foi verificada a presença de bolor e levedura na totalidade das amostras analisadas. Conclui-se que as marcas avaliadas das amostras de farinhas estavam de acordo com os padrões microbiológicos recomendados pela Agência Nacional de Vigilância Sanitária.

Palavras chave: farinha de trigo, avaliação microbiológica, alimentos.

\section{Microbiological quality of wheat (Triticum aestivum) sold in the city of Cascavel (Paraná)}

Cereals, especially wheat flour, foods are susceptible to contamination by different etiologic agents. The control of hygiene is the way to avoid serious consequences for human health. With this concern was aimed to evaluate the microbiological quality of wheat flours sold in major supermarkets of Cascavel (PR). For this purpose, samples of five brands of flour named as A, B, C, D, E and more commercialized in the city of Cascavel/ Pr, were collected and subjected to microbiological evaluation to detect total coliforms, the technique of multiple tubes Number More probable. The count of yeasts and molds was done by plating on potato dextrose agar. According to data analyzed by the Tukey test at 5\%, and the brand differs from other coliforms on the variable. We did not detect the presence of the contaminant Salmonella in any of the brands. However, it was observed

\footnotetext{
${ }^{1}$ Docente do Curso de Graduação de Nutrição e Pós-Graduação em Segurança Alimentar. Universidade Federal da Fronteira Sul - UFFS. Correspondência: Av. Edmundo Gaievski no 1.000, CEP. 85770-000. Realeza, Paraná, Brasil.Tel. (45) 99884848. E-mail: alexandre.moura@uffs.edu.br

2 Graduação em Ciências Biológicas. Faculdade Assis Gurgacz - FAG. Correspondência: Av. das Torres no 500, CEP. 85806-095 - Cascavel, Paraná, Brasil. E-mail: aletha.tasca@gmail.com

${ }^{3}$ Docente do Curso de Graduação de Ciências Biológicas e Mestrado em Manejo e Conservação. Universidade Estadual do Oeste do Paraná - UNIOESTE. Correspondência: Rua Universitária no 1.619. Caixa Postal 701. Jardim Universitário - CEP. 85806-095. Cascavel, Paraná, Brasil. E-mail: fabiana.pinto@unioeste.br

${ }_{4}^{4}$ Docente do Curso de Graduação em Ciências Biológicas. Universidade Federal da Fronteira Sul - UFFS. Correspondência: Av Edmundo Gaievski no 1.000, CEP. 85770-000. Realeza, Paraná. Brasil. E-mail: izabel.soares@uffs.edu.br

${ }^{5}$ Docente do Curso de Graduação em Licenciatura em Matemática. Universidade Tecnológica Federal do Paraná, Campus Toledo. Correspondência: Rua Cristo Rei no 19 - CEP. 85902-490. Toledo, Paraná, Brasil. E-mail: rosangelaa@utfpr.br
} 
the presence of mold and yeast in the samples analyzed. We conclude that the marks of the flour samples evaluated were within the microbiological standards recommended by the National Agency for Sanitary Vigilance.

Key-words: wheat flour, microbiological analysis, food.

\section{INTRODUÇÃO}

Os cereais, em especial, a farinha de trigo são componentes essenciais na dieta humana, pois consiste principalmente de amido (70-75\%), água (14\%) e proteínas (10-12\%). Também apresenta em menor quantidade polissacarídeos não amiláceos (2-3\%) e lipídeos $(2 \%)$ [1]. Este cereal rico em carboidratos, vitaminas e minerais [2,3] é empregado na elaboração de alimentos consumidos diariamente, na forma de pães, biscoitos, bolos e massas, alimentos que integram parte da base da pirâmide alimentar. Entretanto, a farinha de trigo pode se tornar um veículo para contaminantes durante $\mathrm{o}$ processo de preparos industriais $\mathrm{e}$ domésticos, inclusive micotoxinas que porventura não sejam eliminadas durante a moagem $[4,5]$.

Dentre os microrganismos que podem contaminar os grãos estão as bactérias esporuladas como Bacillus cereus ${ }^{[6]}$ o grupo de coliformes destacando Escherichia coli e a Salmonella spp., os quais podem causar diarreia, náuseas, dores abdominais e febre nos seres humanos. Os bolores também podem causar toxicidade alimentar, visto que determinadas espécies, em condições de armazenamento e conservação deficientes, produzem micotoxinas na superfície dos alimentos [7,8].

A identificação dos microrganismos envolvidos na produção e deterioração de alimentos possibilita o conhecimento correto das características metabólicas e fisiológicas dos microrganismos permitindo o uso de técnicas adequadas de processamento e conservação dos alimentos, garantindo uma qualidade microbiológica segura do alimento, evitando danos à saúde $[9,10,11]$.

Diante do exposto, o objetivo deste estudo foi verificar as condições higiênico-sanitárias da farinha de trigo comercializada nos principais supermercados da cidade de Cascavel (PR), por meio de análise microbiológica para coliformes totais e coliformes a $45^{\circ} \mathrm{C}$, contagem de bolores e leveduras, comparando os resultados obtidos frente aos padrões microbiológicos de qualidade exigidos pelo Ministério da Saúde, através da ANVISA [12].

\section{METODOLOGIA}

As análises foram realizadas no laboratório de Análises Microbiológicas na Faculdade Assis Gurgacz FAG, na cidade de Cascavel (PR). Foram analisadas 15 amostras de farinha de trigo das cinco marcas mais comercializadas pelos supermercados na cidade de no período de julho a dezembro de 2011.

De cada amostra foram pesados $25 \mathrm{~g}$ e depois transferidas para um homogenizador contendo $225 \mathrm{~mL}$ de água peptonada estéril previamente preparada a 0,1\%. A partir desta diluição foram feitas diluições subseqüentes necessárias à análise do produto. As amostras sofreram diluições $10^{-1}$ até $10^{-3}$ para determinação de coliformes e $10^{-1}$ até $10^{-4}$ para contagem de bolores e leveduras. Para o teste de colimetria (coliformes totais - CT e coliformes termotolerantes ou fecais - $\mathrm{CF}$ ) utilizou-se a técnica dos tubos múltiplos com determinação do Número Mais Provável (NMP/g) e bioquímicas através do meio Rugai com Lisina e Citrato de Simmons, contagem de bolores e leveduras segundo a American Public Health Association [13].

O resultado foi calculado multiplicando-se o valor encontrado na tabela do Número Mais Provável [14], pela menor diluição que contenha resultado positivo e reportado como Número Mais Provável por grama (NMP/g) de farinha. Para pesquisar a presença de Salmonella sp., foi realizado o pré-enriquecimento e posterior enriquecimento seletivo nos meios Rappaport-Vassiliadis com incubação a $36^{\circ} \mathrm{C}$ e Tetrationato com incubação a $42,5^{\circ} \mathrm{C}$, ambos por 24/48h e para confirmação utilizou-se os meios seletivos SS e CHRO Magar Salmonela. Foi usado o meio Ágar Batata Dextrose Acidificado para contagem de bolores e leveduras. Dos tubos que apresentaram turvação e gás no tubo de Durham, alíquotas foram semeadas com o auxilio de alça bacteriológica, pela técnica de esgotamento por estrias descontínuas, em 
placas de Petri contendo meio de Teague - (EMS) Ágar Eosina Azul de Metileno e incubadas a $37^{\circ} \mathrm{C}$ por 24 horas.

Para identificação de E. coli e Citrobacter spp. as colônias foram submetidas às provas bioquímicas nos meios Rugai com Lisina e Citrato de Simmons sendo os tubos incubados a $37^{\circ} \mathrm{C}$ por $24 \mathrm{~h}$. Foram realizadas as leituras das provas acima mencionadas obtendo-se resultados para: fermentação da glicose; descarboxilação da lisina; desaminação da fenilalanina; produção de indol a partir do triptofano; presença de gás, $\mathrm{H} 2 \mathrm{~S}$, produção de urease e utilização do citrato como única fonte de energia.

Os resultados obtidos foram comparados com dados da Resolução RDC 12, de 02 de janeiro de 2001, do Regulamento Técnico sobre os Padrões Microbiológicos para Alimentos [12].

Para análise estatística, os dados de contagem bacteriana foram transformados em $\log$ da base 10 . Os dados transformados foram utilizados para análise de variância (ANOVA) com amostras independentes. $\mathrm{O}$ teste de Tukey foi aplicado para comparação de médias onde foi utilizado o programa estatístico (SAS, 6.0, 1998) $[15]$.

\section{RESULTADOS E DISCUSSÃO}

As amostras analisadas foram compostas de farinha de trigo especial, devido ao maior teor de cinzas, fator indicativo de maior teor de sais minerais no alimento em comparação com a farinha comum $[16,17]$.

Os resultados das avaliações microbiológicas das amostras de farinha de trigo coletadas nos estabelecimentos, estão dispostos na Tabela mostrada na sequencia.

Tabela. Comparação dos dados da avaliação microbiológica das amostras de farinha de trigo de cinco marcas mais comercializadas no município de Cascavel (Paraná).

\begin{tabular}{c|c|c|c|c}
\hline Marca & Mesófilas & Coliformes Totais & $\begin{array}{c}\text { Coliformes } \\
\text { Termotolerantes }\end{array}$ & Bolor e levedura \\
\hline A & $402,03 \pm 186,25 \mathrm{a}$ & $260,23 \pm 126,67 \mathrm{a}$ & $121,33 \pm 156,85 \mathrm{ab}$ & $379,20 \pm 94,47 \mathrm{a}$ \\
$\mathrm{B}$ & $379,07 \pm 172,66 \mathrm{a}$ & $278,06 \pm 173,45 \mathrm{a}$ & $480,11 \pm 229,26 \mathrm{a}$ & $245,65 \pm 118,16 \mathrm{a}$ \\
$\mathrm{C}$ & $382,93 \pm 77,62 \mathrm{a}$ & $469,05 \pm 277,60 \mathrm{a}$ & $230,13 \pm 305,96 \mathrm{ab}$ & $319,58 \pm 171,27 \mathrm{a}$ \\
$\mathrm{D}$ & $424,68 \pm 132,39 \mathrm{a}$ & $422,53 \pm 306,24 \mathrm{a}$ & $152,83 \pm 237,10 \mathrm{ab}$ & $321,08 \pm 156,88 \mathrm{a}$ \\
$\mathrm{E}$ & $339,47 \pm 62,99 \mathrm{a}$ & $73,10 \pm 179,05 \mathrm{~b}$ & $28,90 \pm 70,79 \mathrm{~b}$ & $223,93 \pm 149,79 \mathrm{a}$ \\
\hline Anova $p$-valor & 0,859 & $0,001 *$ & $0,015^{*}$ & 0,337 \\
\hline
\end{tabular}

Observa-se baixo índice de contaminação por coliformes totais na totalidade das amostras, entretanto, na análise para coliformes termotolerantes, as marcas de farinhas analisadas indicaram diferença significativa pelo teste de Tukey $(5 \%)$. A maior diferença pode ser visualizada entre as marcas B e E, sendo que a marca $\mathrm{B}$ apresentou a maior média e a marca $\mathrm{E}$ a menor média. A diferença entre Coliformes totais e fecais é restringida à capacidade de fermentação da lactose, com produção de gás, em $24 \mathrm{~h}$ a $44,5-45,5^{\circ} \mathrm{C}$ por coliformes fecais. Esse grupo inclui pelo menos quatro gêneros, Escherichia, Enterobacter, Citrobacter e Klebsiella, sendo os gêneros Enterobacter, Citrobacter e Klebsiella, considerados por alguns pesquisadores provenientes de outra origem que não a fecal [18,19]. E. coli é a mais conhecida, sendo seu habitat primário o trato gastrintestinal por este motivo é a indicadora de contaminação fecal, em alimentos processados ${ }^{[20]}$ e contaminação causada, por exemplo, por roedores, durante a estocagem [21]. 
A contagem elevada de coliformes totais é um indicativo de falhas nas boas práticas de manipulação e nas condições higiênico-sanitárias, demonstrando, assim, possíveis presenças de diferentes patógenos [ $[$. A Resolução RDC 12, de 02 de janeiro de 2001, não estabelece um limite para coliformes totais ${ }^{[12]}$.

Já para as variáveis bolor e levedura as amostras analisadas apresentaram contaminação, porém, sem diferença estatística entre as marcas analisadas (Tabela). Esta contaminação poderia ser atribuída a diversos fatores, como eventuais deficiências no processamento, na sua manipulação e ainda durante a estocagem. Cabe ressaltar que, mesmo adequadamente embalados e protegidos da umidade, estes microrganismos são resistentes e podem viver por muito tempo em baixas concentrações de água [22]. As condições inadequadas de armazenamento de cereais não apenas favorecem a proliferação dos fungos, mas também dos ácaros e insetos, que podem deteriorar os produtos [23].

Quanto às bactérias mesófilas aeróbias foi evidenciado contaminação em todas as amostras analisadas de todas as marcas. Estas bactérias sobrevivem nas condições ambientais normais, sua quantidade nos alimentos indica a condição sanitária. A legislação brasileira estabelece limite máximo de 1000 Unidades Formadoras de Colônia (UFC) tanto para o Bacilus cereus quanto para bolores e leveduras, para cada grama de farinha. O limite estabelecido para bactérias mesófilas é de 100.000 UFC, para cada grama de farinha [20]. Das bactérias que podem contaminar a farinha apenas o Bacillus cereus tem o solo como reservatório [24], indicando que a contaminação por esta bactéria pode estar relacionada ao processo de preparação da farinha de trigo. As micotoxinas, principalmente zearalenona e ocratoxina, constituem o perigo de maior importância [25] devido à sua termorresistência e capacidade de resistir a todos os procedimentos para eliminação de fungos.

A Salmonella spp. é uma bactéria entérica responsável por graves intoxicações alimentares, sendo um dos principais agentes envolvidos em surtos registrados em vários países [26]. A sua presença em alimentos é um relevante problema de saúde pública que não deve ser tolerado nos países desenvolvidos, principalmente naqueles em desenvolvimento, porque os sinais e sintomas podem ser mal diagnosticados, sobrecarregando ainda mais todo o sistema de saúde. O regulamento técnico sobre padrões microbiológicos, já citado anteriormente, estabelece um parâmetro qualitativo para Salmonella sp. (em 25g). Se presente, este microrganismo, independente da quantidade, a amostra não estará de acordo com a legislação. Nas análises realizadas, não foi detectada presença de Salmonella sp. (em $25 \mathrm{~g}$ ), ou seja, as amostras atenderam ao padrão estabelecido pela legislação [12].

A conservação e proteção dos alimentos também são garantidas por embalagens que precisam ser resistentes, garantir as características dos alimentos e devem permitir a conservação adequada dos mesmos, pelo tempo especificado para o produto na embalagem [27,28]. Os alimentos embalados incorretamente podem deteriorar e sofrer contaminação, bem como incorporar aos produtos elementos nocivos à saúde principalmente de natureza química, como, por exemplo, pela ação de substâncias acidulantes ou pela acidez natural do próprio alimento [28]. A falta de requisitos básicos, como temperatura adequada e embalagem correta resulta em descoloração do alimento, formação de bolores, infestação por insetos e roedores o que tornará o produto impróprio para consumo, representando riscos a saúde do consumidor ${ }^{[29]}$.

\section{CONCLUSÕES}

Os resultados obtidos neste trabalho permitem concluir que embora os índices de contaminação por coliformes totais estejam inferiores aos valores estabelecidos nas normas vigentes, o índice de contaminação por coliformes termotolerantes em todas as marcas analisadas estão bem elevados.

As contaminações por bolores e leveduras estão presentes em todas as amostras e bactérias mesófilas aeróbias foram evidenciadas nas amostras das cinco marcas.

O trigo é o segundo cereal mais produzido no mundo, com significativo peso na economia brasileira principalmente nas regiões Sul, Sudeste e CentroOeste, onde ocorre a maior produção do grão. Com estimativa governamental de aumento no consumo de trigo e investimentos na auto-suficiência da produção interna do cereal, a qualidade microbiológica do cereal deve receber especial atenção, visando a produção e consumo de um alimento que propicie segurança e seja fonte importante de nutrientes. 


\section{REFERÊNCIAS}

[1] Goesaert H, Brijs K, Veraverbeke WS, Courtin CM, Gebruers K, Delcour JA. Wheat flour constituients: how they impact bread quality, and how to impact their funcionality. Trends in Food Science \& Technology, 2005;(16):12-30.

[2] Miranda $\mathrm{MZ}, \mathrm{Al}$ Dash A. Farinha integral de trigo germinado: características nutricionais e estabilidade ao armazenamento. Ciênc. Tecnol. Aliment., 2002;22(3):216223.

[3] Bernardi E, Caldeira MF, Nascimento JS. Identificação de fungos filamentosos em erva-mate (ilex paraguariensis st. hil.). Arq Inst.Biol., 2005;72(4):489-493.

[4] Pereira ML, Chang YK. Contaminantes do trigo e farinha e medidas de sanitização na indústria de moagem e panificação. Higiene Alimentar, 1993;7(26):20-29.

[5] Pelczar Jr M, Chan ECS, Krieg NR. Microbiologia: Conceitos e Aplicações. 2 $2^{\mathrm{a}}$ edição, v.02. São Paulo: McGraw-Hill, 1997.

[6] Robinson RK, Phill MAD. Microbiologia lactológica. Zaragoza: Acribia, 1987.

[7] Leitão MFF. Tratado de microbiologia: Microbiologia de Alimentos, Sanitária e Industrial. São Paulo: Manole, v.1, 1988.

[8] Schintu M, Meloni P, Sal M, Contu A. Esperienze sul controllo microbiologico di paste fresche di produzione artigianale - L'Igiene Moderna, 1996;(105):55-62.

[9] Banwart GJ. Basic food microbiology. In: Westport CT: The AVI Publishing Company, Inc., p.51-62., 1981.

[10] Franco B, Landgraf M. Microbiologia dos Alimentos. São Paulo: Atheneu, 1996.

[11] Pinto AFMA. Papel dos Microrganismos na Produção e na Transformação de Alimentos. Terra Fértil, 1996.

[12] Brasil, Resolução RDC no 12, de 02/01/2001. Estabelece regulamento técnico sobre os padrões microbiológicos para alimentos [acesso em 26 março 2012]. Disponível em: http:/ /www.anvisa.org.br

[13] Apha. American Public Health Association Compendium of Methods for the Microbiological Examination of Foods. $4^{\mathrm{a}}$ edição. Washington DC: APHA, 2001.
[14] Speck ML. Compendium of methods for the microbiological examination of foods. Washington D.C.: APHA, 1976.

[15] SAS Institute Inc. SAS/STAT Guide for personal Computers. Version 6.0. Cary, NC., 1998.

[16] Ciacco CF, Chang YK. Tecnologia de massas alimentícias. São Paulo: Ícone, 127p, 1986

[17] Zhang D, Moore WR. Effect of Wheat Bran Particle Size on Dough Rheological Properties. J. Sci. Food Agric. 1997,(74):490-496.

[18] Macêdo JAB. Águas \& Águas. Juiz de Fora: ORTOFARMA, 505p, 2000.

[19] Levine MM. Escherichia coli that causes diarhoea enterotoxigenic, enteropathogenic, enteroinvasive, enterohaemorragic and enteroadherent. Journal Infections Disease, U.S.A., 1987;(155):377- 389.

[20] Silva N. Manual de métodos de análise microbiológica de alimentos. São Paulo: Livraria Varela,1997, p. 31.

[21] Wright EJ, Webb MC, Highley, E. Stored grain in Australia. Proceedings of the Australian Postharvest Technical Conference, Canberra, 25-27 June, 2003.

[22] Ferreira Neto CJ, Figueirêdo RMF, Queiroz AJM. Avaliação sensorial e da atividade de água em farinhas de mandioca temperadas. Ciênc Agrotec., Lavras, 2005;29(4):795-802.

[23] Atui MB, Lazzari FA, Zamboni CQ. Efeito do processamento do milho em grão no nível de matérias estranhas encontradas no grits e fubá. Rev Inst Adolfo Lutz, 1998;(57):57-63.

[24] Molard R, Gahagnier B. Microbiologia em moinhos. Ceará: SENAI/Centro Regional de Treinamento em Moagem e Panificação, 1993. p.17-51.

[25] Vieira AP, Badiale-Furlong E, Oliveira ML. Ocorrência de micotoxinas e características físicoquímicas em farinhas comerciais. Ciênc Tecnol Alim. 1999;(19):221-225.

[26] Maijala R, Ranta J, Seuna E. The efficiency of the Finnish Salmonella Control Programme. Food Control 2005;16(8):669-675.

[27] Baruffaldi R, Oliveira MN. Fundamentos de tecnologia dos alimentos. São Paulo: Atheneu, v. 3, 1998, 317p. 
[28] Germano PML, Germano MIS. Higiene e Vigilância Sanitária de Alimentos. São Paulo: Varela, 2001. 629p.
[29] Hazelwood D, McLEAN AC. Manual de higiene para manipuladores de alimentos. São Paulo: Varela, 1996. 140p. 